\title{
Source identification of polycyclic aromatic hydrocarbons in sediments of a creek around a flow station
}

\author{
A. K. Inengite $\cdot$ N. C. Oforka $\cdot$ C. Osuji Leo
}

Received: 17 June 2011/Revised: 10 December 2011/Accepted: 29 March 2012/Published online: 5 February 2013

(C) Islamic Azad University (IAU) 2013

\begin{abstract}
Sources of the sixteen polycyclic aromatic hydrocarbons (PAHs) in the United States Environmental Protection Agency priority pollutants list were determined in sediments of Kolo Creek using diagnostic ratios of parent PAHs[phenanthrene/phenanthrene + anthracene; fluoranthene/fluoranthene + pyrene; benz(a) anthracene/ benz(a) anthracene + chrysene and indeno(1,2,3-d)pyrene/ indeno(1,2,3-cd)pyrene + benzo(ghi)pyrelene]. The study was conducted over four seasons (dry, late dry, rainy and late rainy seasons). Applying cross plots of the diagnostic ratios revealed that PAHs in Kolo Creek sediment have pyrogenic origins except in the rainy season that had petrogenic origins. Comparison of diagnostic ratio values obtained from this study with literature values enabled the further classification into types of pyrogenic and/or petrogenic sources. While the pyrogenic sources of PAHs were mainly as a result of Grass/Wood combustion, the petrogenic PAHs were as result of drained diesel and lubricating oil. The predicted sources corresponded with the prevailing human activities in the vicinity, especially samples collected near a petrol station and an abattoir. This study further affirms the simplicity and accuracy of the use of diagnostic ratios for PAHs source prediction.
\end{abstract}

Keywords Aquatic environment · Gas flaring · Organic pollutants

\footnotetext{
A. K. Inengite $(\square)$

Department of Chemical Sciences, Niger Delta University, Wilberforce Island, Bayelsa State, Nigeria e-mail: ainengit@yahoo.com

N. C. Oforka · C. Osuji Leo Department of Pure and Industrial Chemistry, University of Port Harcourt, Choba, Nigeria
}

\section{Introduction}

Polycyclic aromatic hydrocarbons (PAHs) are ubiquitous in the environment and can travel long distances from their sources (Lunde and Bjorseth 1977; Halsall et al. 2001), therefore separation of PAHs based on their origins poses a great challenge in environmental studies, especially when there are cumulative impacts on the environment from various sources of PAHs (Readman et al. 1987; Yunker et al. 2002), each having adverse health effects (Yunker et al. 2002; Zhang et al. 2004; Ana et al. 2009). Therefore, there is a desperate need to evaluate and determine the sources of PAHs in the environment to enable proper monitoring and control of emissions into the environment.

PAHs can be classified as being of petrogenic (petroleum) or pyrogenic (combustion) origins; they can also be classified as being of natural and anthropogenic origins. Anthropogenic PAHs, however, contribute the major proportion of PAHs in the environment (Fine et al. 2001; Aichner et al. 2007; Morillo et al. 2008).

Sixteen PAHs listed in the United States Environmental Protection Agency (USEPA) priority pollutants list were considered. They include: naphthalene(Naph); acenaphthene (Ace); acenapthylene (Acen); fluorene (Flu); phenanthrene (Phe); anthracene (Ant); fluoranthene (Fluo); pyrene (Pyr); 1,2-benzanthracene (BaA); chrysene (Chry); benzo(b)fluorathene (benzo(b)); benzo(k)fluoranthene (benzo(k)); benzo(a) pyrene (BaP); 1,2,5,6-dibenzanthracene (Diben); indeno(1,2,3-cd) pyrene (Ind); 1, 12-benzopyrelene (BghiP). Various methods are being applied in source identification and apportionment of PAHs. These include emission inventory modelling approaches, multivariate statistical methods and the use of diagnostic ratios (DRs) of selected PAHs (Li and Kamens 1993; Westerholm and Li 1994; Sjogren et al. 1996; Wang et al. 1999; 
Dvorska et al. 2011). Source identification using DRs holds advantages due to the ease of application (Yunker et al. 2002; Morillo et al. 2008; Wang et al. 2010; Dvorska et al. 2011) and unlike inventory modelling approaches; DRs do not rely on emissions inventories which may not be available in most countries especially developing countries.

Morillo et al. (2008) determined the sources of PAHs in urban environments of Sevilla (Southern Spain) using principal mass $\mathrm{PAH}$ ratios and low molecular weight (LMW)/high molecular weight (HMW) ratios, while Re'-Poppi and Santiago-Villa (2005) applied PAHs ratios as source determination of PAHs in ambient air of Campo Grande City, Brazil. Four PAHs ratios; Phe/Phe + Ant; Fluo/Fluo + Pyr; BaA/BaA + Chry and Ind/Ind + BghiP were applied to cover for both LMW and HMW PAHs.

Due to the overlap of characteristic PAH profiles from each source and selective decay of more labile compounds, instead of using single ratio, coupling of two is helpful to provide better estimation of PAH sources (Yunker et al. 2002; Lehndorff and Schwark 2004).

In this study, for the first time, PAHs DRs (Phe/Phe + Ant; Fluo/Fluo + Pyr; BaA/BaA + Chry and Ind/Ind + BghiP) were applied for source determination of PAHs in Kolo Creek surface sediments. The study was conducted within April 2008 to January 2009.

Kolo Creek is a fresh water non-tidal creek that flows through a region of Niger Delta that has been urbanised and industrialised due to the quest for crude oil and natural gas, a natural resource that is in abundance in the area and also a likely source of PAHs into the environment. As result of the exploitation and exploration of crude oil and natural gas, Kolo Creek receive loads of human and industrial effluents which may be detrimental to the quality of the Creek (Inengite et al. 2010a).

It is noteworthy that Kolo Creek serves as a source of water for domestic use and also serves as a recreational facility to the inhabitants of the adjoining communities.

\section{Materials and methods}

Sampling sites

Nine points were sampled, eight along Kolo Creek and one point located at Epie Creek (Fig. 1). Three points (SS1, SS2, SS5) were around Kolo Creek Flow station and SS4, SS7 and SS8 were within Imiringi, Otuasega and Oruma communities, respectively; while SS3 and SS6 were within uninhabited farmland environments. SS9 was in Epie Creek within Tombia Junction which is relatively urbanised when compared to Imiringi, Otuasega and Oruma. Tombia Junction is situated within Yenagoa with an estimated population of 152,817 as at 2004 (Tamuno 2005). While the other communities were pre-occupied by mainly domestic activities except for the flow station; Tombia junction is busy with a lot of vehicular emissions from automobiles.

The sampling field data are as shown in (Table 1).

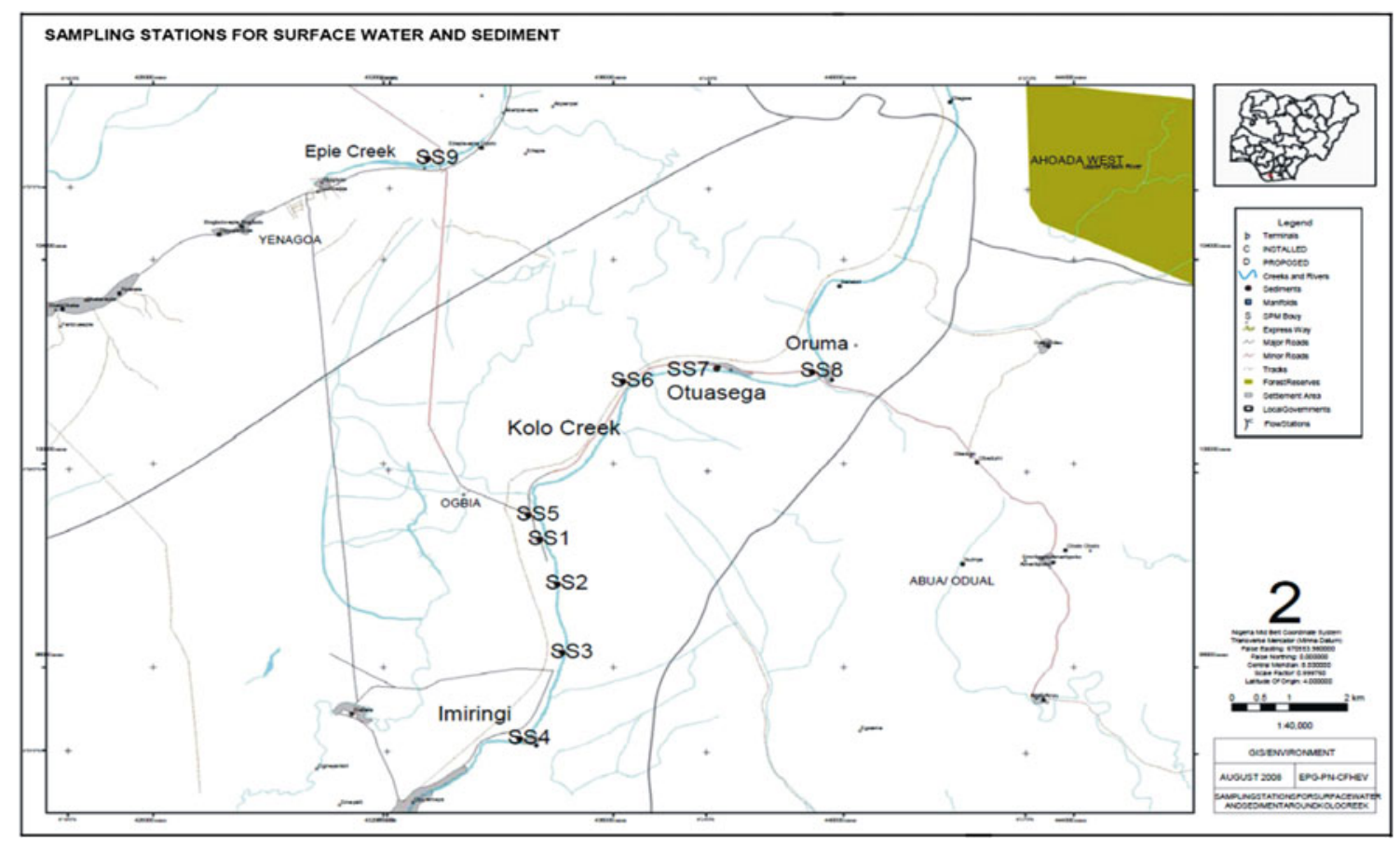

Fig. 1 Map showing sampling stations 
Table 1 Sampling field data for sediment

\begin{tabular}{|c|c|c|c|c|c|}
\hline $\begin{array}{l}\text { Sampling stations } \\
\text { (SS) }\end{array}$ & Dates sampled & Times sampled & Station location/description & Latitude (N) & Longitude (E) \\
\hline SS1 & $\begin{array}{l}\text { 6th April, 2008; 29th June, } 2008 \\
\text { 19th Oct., 2008; 24th Jan., } 2009\end{array}$ & $\begin{array}{l}\text { 10:03 am; 9:45 am } \\
10: 30 \mathrm{am} ; 9: 30 \mathrm{am}\end{array}$ & $\begin{array}{l}\text { Kolo Creek flow station/gas } \\
\text { flaring point }\end{array}$ & $4^{\circ} 53^{\prime} 15.855^{\prime \prime}$ & $6^{\circ} 22^{\prime} 25.640^{\prime \prime}$ \\
\hline SS2 & $\begin{array}{l}\text { 6th April, 2008; 29th June, } 2008 \\
\text { 19th Oct., 2008; 24th Jan., } 2009\end{array}$ & $\begin{array}{l}\text { 10:40 am; 10:32 am } \\
11: 05 \mathrm{am} ; 9: 50 \mathrm{am}\end{array}$ & $\begin{array}{l}\text { Kolo Creek Flow station/field } \\
\text { logistics base }\end{array}$ & $4^{\circ} 52^{\prime} 47.289^{\prime \prime}$ & $6^{\circ} 22^{\prime} 35.497^{\prime \prime}$ \\
\hline SS3 & $\begin{array}{l}\text { 6th April, 2008; 29th June, } 2008 \\
\text { 19th Oct., 2008; 24th Jan., } 2009\end{array}$ & $\begin{array}{l}\text { 11:10 am; 11:05 am } \\
11: 30 \mathrm{am} ; 10: 30 \mathrm{am}\end{array}$ & $\begin{array}{l}\text { Imiringi/Roadside and fallow } \\
\text { bushy area }\end{array}$ & $4^{\circ} 52^{\prime} 03.614^{\prime \prime}$ & $6^{\circ} 22^{\prime} 38.551^{\prime \prime}$ \\
\hline SS4 & $\begin{array}{l}\text { 6th April, 2008; 29th June, } 2008 \\
\text { 19th Oct., 2008; 24th Jan., } 2009\end{array}$ & $\begin{array}{l}11: 45 \mathrm{am} ; 11: 40 \mathrm{am} \\
12: 00 \mathrm{pm} ; 11: 05 \mathrm{am}\end{array}$ & $\begin{array}{l}\text { Imiringi/Inhabited community } \\
\text { with domestic activities }\end{array}$ & $4^{\circ} 51^{\prime} 08.229^{\prime \prime}$ & $6^{\circ} 22^{\prime} 14.620^{\prime \prime}$ \\
\hline SS5 & $\begin{array}{l}\text { 6th April, 2008; 29th June, } 2008 \\
\text { 19th Oct., 2008; 24th Jan., } 2009\end{array}$ & $\begin{array}{l}12: 35 \mathrm{pm} ; 12: 30 \mathrm{pm} \\
12: 45 \mathrm{pm} ; 11: 30 \mathrm{am}\end{array}$ & $\begin{array}{l}\text { Kolo Creek Flow station/ } \\
\text { roadside, fallow bush with } \\
\text { farmlands }\end{array}$ & $4^{\circ} 53^{\prime} 31.426^{\prime \prime}$ & $6^{\circ} 22^{\prime} 19.121^{\prime \prime}$ \\
\hline SS6 & $\begin{array}{l}\text { 6th April, 2008; 29th June, } 2008 \\
\text { 19th Oct., 2008; 24th Jan., } 2009\end{array}$ & $\begin{array}{l}1: 25 \mathrm{pm} ; 1: 25 \mathrm{pm} \\
1: 48 \mathrm{pm} ; 12: 40 \mathrm{pm}\end{array}$ & $\begin{array}{l}\text { Otuasega/roadside and } \\
\text { farmland }\end{array}$ & $4^{\circ} 54^{\prime} 56.765^{\prime \prime}$ & $6^{\circ} 23^{\prime} 12.185^{\prime \prime}$ \\
\hline SS7 & $\begin{array}{l}\text { 6th April, 2008; 29th June, } 2008 \\
\text { 19th Oct., 2008; 24th Jan., } 2009\end{array}$ & $\begin{array}{l}2: 10 \mathrm{pm} ; 2: 15 \mathrm{pm} \\
2: 45 \mathrm{pm} ; 1: 50 \mathrm{pm}\end{array}$ & $\begin{array}{l}\text { Otuasega/inhabited community } \\
\text { with domestic activities }\end{array}$ & $4^{\circ} 55^{\prime} 05.089^{\prime \prime}$ & $6^{\circ} 24^{\prime} 04.921^{\prime \prime}$ \\
\hline SS8 & $\begin{array}{l}\text { 6th April, 2008; 29th June, } 2008 \\
\text { 19th Oct., 2008; 24th Jan., } 2009\end{array}$ & $\begin{array}{l}\text { 3:05 pm; 3:05 pm } \\
3: 40 \mathrm{pm} ; 3: 05 \mathrm{pm}\end{array}$ & Oruma/inhabited community & $4^{\circ} 55^{\prime} 03.037^{\prime \prime}$ & $6^{\circ} 24^{\prime} 58.92^{\prime \prime}$ \\
\hline SS9 (Tombia) & $\begin{array}{l}\text { 6th April, 2008; 29th June, } 2008 \\
\text { 19th Oct., 2008; 24th Jan., } 2009\end{array}$ & $\begin{array}{l}4: 10 \mathrm{pm} ; 4: 15 \mathrm{pm} \\
4: 40 \mathrm{pm} ; 4: 00 \mathrm{pm}\end{array}$ & $\begin{array}{l}\text { Tombia junction Yenagoa/ } \\
\text { urbanised community, busy } \\
\text { roadside, petrol station and } \\
\text { abattoir }\end{array}$ & $4^{\circ} 57^{\prime} 18.776^{\prime \prime}$ & $6^{\circ} 21^{\prime} 21.604^{\prime \prime}$ \\
\hline
\end{tabular}

$L D($ late dry season $)=6$ th April, 2008; $R$ (rainy season $)=29$ th June, 2008; $L R$ (late rainy season $)=19$ th Oct. 2008; $D($ dry season $)=24$ th Jan. 2009

\section{Sampling}

Sediment samples were collected using a stainless steel Van Veen grab sampler. Triplicate sediment samples were collected at each point to form one composite sample and another composite sample collected about $5 \mathrm{~m}$ away from the first point at the same sampling station, forming a total of 72 composite sediment samples for the four sampling seasons. The average PAHs concentrations were as stated in (Table 2). The samples were wrapped in aluminium foil stored in an ice chest and taken to the laboratory and stored at $-20{ }^{\circ} \mathrm{C}$ prior to analysis.

\section{Extraction of PAHs from sediment samples}

The samples were dried, crushed and sieved using $0.5 \mathrm{~mm}$ sieve. $2.0 \mathrm{~g} \pm 0.01$ of samples were weighed and spiked with pre-deuterated PAHs mixture (naphthalene-d8, phenanthrene-d10, chrysene-d12, and perylene-d12) as an internal standard, to determine the extraction efficiency. The recovery was $>90 \% .10 \mathrm{ml}$ of extraction solvent (pentane) was added into the samples and mixed thoroughly and allowed to settle. The mixtures were carefully filtered into clean solvent rinsed extraction bottles using filter paper fitted into Buchner funnels. The extracts were concentrated to $2 \mathrm{ml}$ using a rotary evaporator and then transferred for clean-up/separation.

\section{Sample clean-up}

In a $10-\mathrm{mm}$ id $\times 250 \mathrm{~mm}$ long chromatographic column, $1 \mathrm{~cm}$ of moderately packed glass wool was placed at the bottom. Slurry of $2 \mathrm{~g}$ activated silica gel in $10 \mathrm{ml}$ of dichloromethane (DCM) was prepared and placed into the chromatographic column. To the top of the column was added $0.5 \mathrm{~cm}$ of sodium sulphate. The column was rinsed with additional $10 \mathrm{ml}$ of DCM. The column was pre-eluted with $20 \mathrm{ml}$ of Pentane; this was allowed to flow through the column for about 2 min until the liquid in the column was just above the sulphate layer. Immediately, $1 \mathrm{ml}$ of the extracted sample was transferred into the column, the extraction bottle was rinsed with $1 \mathrm{ml}$ of pentane and added to the column as well. The stop-cock of the column was opened and the eluent was collected with a 10-ml graduated cylinder. Just prior to exposure of the sodium sulphate layer to air, pentane was added to the column in $1-2 \mathrm{ml}$ increments. Accurately measured volume of $8-10 \mathrm{ml}$ of the eluent was collected. This was labelled "ALIPHATIC". Following recovery of the "ALIPHATIC" fractions just prior to exposure of the sodium sulphate layer, the column 


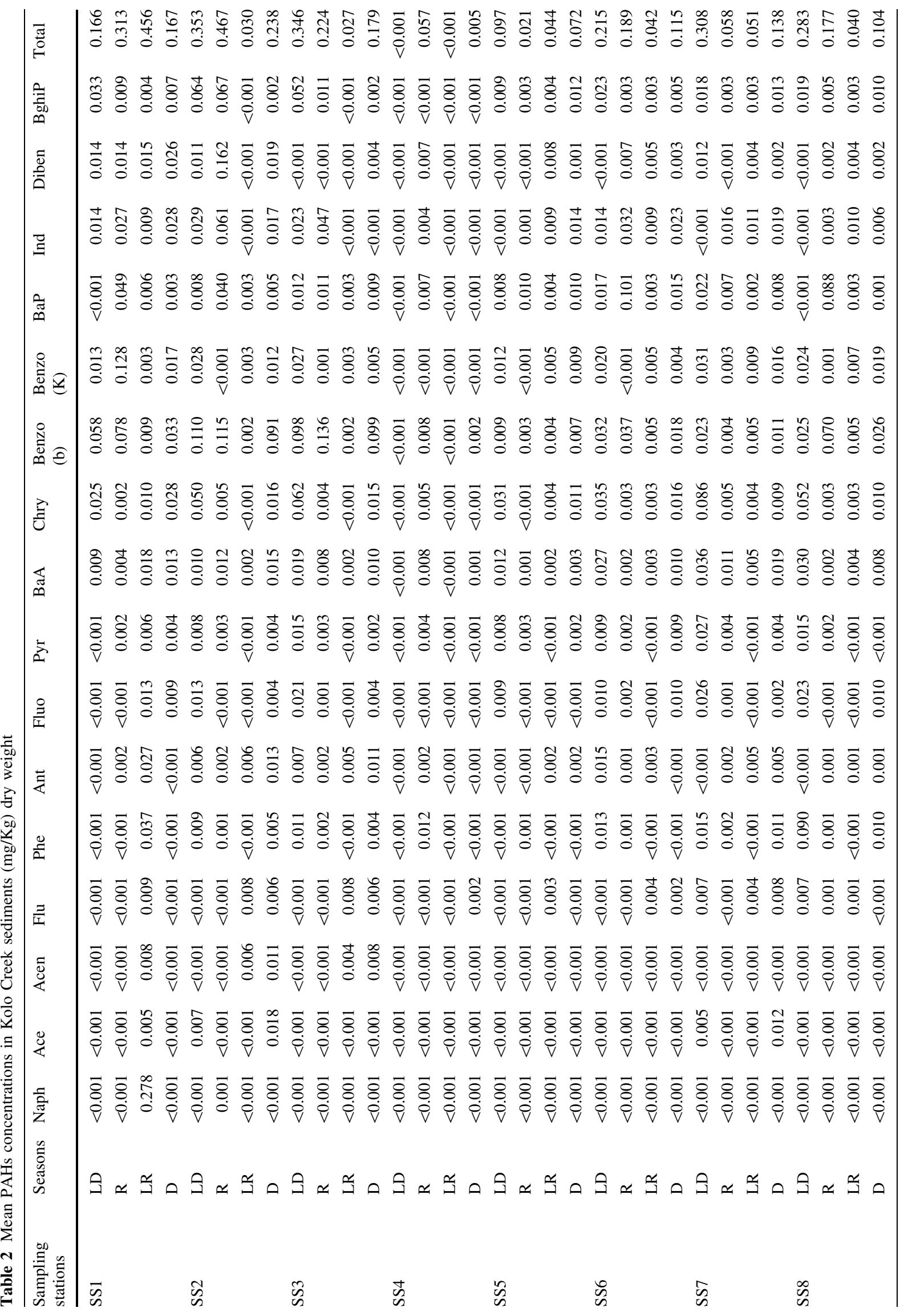




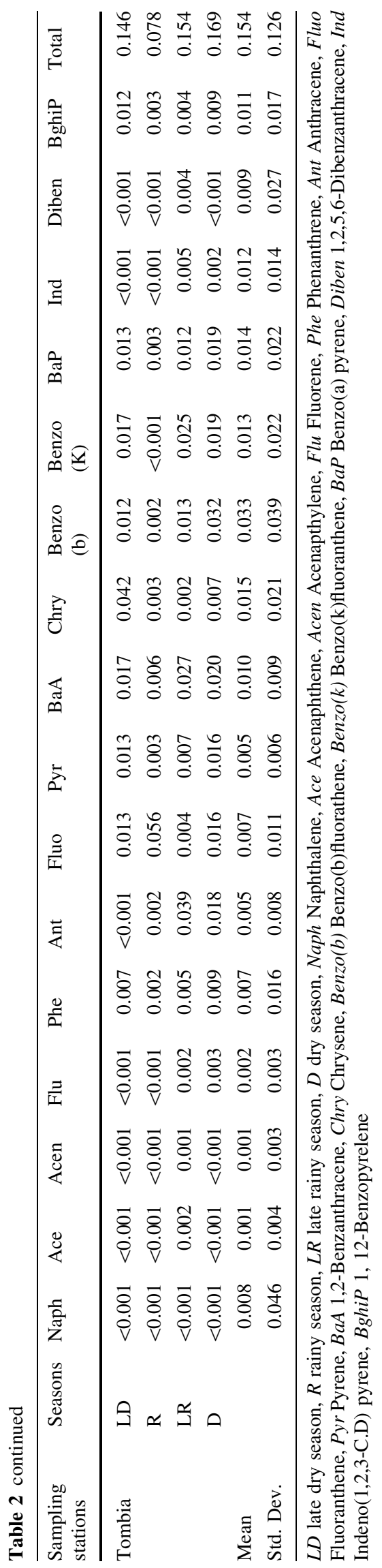

was eluted with 1:1 mixture of propanone and DCM in $1-2 \mathrm{ml}$ increments. Another accurately measured $8-10 \mathrm{ml}$ of the eluent was collected and was labelled "AROMATICS". The "AROMATICS" fraction was concentrated to $1 \mathrm{ml}$ for PAHs analysis using gas chromatography.

Gas chromatographic (GC) analysis

The concentrated "AROMATICS" fractions were transferred into labelled glass vials with teflon rubber crimp caps for GC analysis. $1 \mu \mathrm{l}$ of the concentrated sample was injected by means of hypodermic syringe through a rubber septum into the column. Separation occurs as the vapour constituent partition between the gas and liquid phases. The sample was automatically detected as it emerges from the column (at a constant flow rate) by a flame ionisation detector (FID) whose response is dependent upon the composition of the vapour, by measuring the retention time.

The GC was calibrated by calibration curve method, using standard solutions.

The operational conditions for GC analysis are as stated in Inengite et al. (2010b).

Detector: Hydrogen-35 ml/min; Air- $250 \mathrm{ml} / \mathrm{min}$; Nitrogen-30 $\mathrm{ml} / \mathrm{min}$.

Inlet: Pressure-14.8 psi; Total flow- $65.5 \mathrm{ml} / \mathrm{min}$.

Oven: Initial Temperature $-65{ }^{\circ} \mathrm{C}$; Final Temperature- $325{ }^{\circ} \mathrm{C}$; Run time $-29.0 \mathrm{~min}$.

The limit of detection (LOD) was $0.01 \mu \mathrm{g} / \mathrm{g}$ for the various PAHs studied.

\section{Results and discussion}

The results of the PAHs concentrations in the sediments are as stated in Table 2. The PAHs DRs for the various periods of the year that the study was conducted are as stated in Table 3. Half the values of the detection limit of the gas chromatograph were used to represent values below the detection limit of the gas chromatograph, to take care of missing values.

The choice of Epie Creek (SS9) was to serve as control to Kolo Creek. Within the route of Epie Creek there was no gas flaring, while the major concern in the Kolo Creek axis is the gas flare. However, the presence of the gas flare did not show much difference between the two creeks in terms of PAHs concentration rather there were similarities because both SS1 and SS9 portrayed combustion as the main source of PAHs. Henceforth, for the purposes of source prediction of PAHs, Kolo Creek represent all the sampling stations.

The mean levels of PAHs in Kolo Creek sediment at the time of study was $(0.154 \pm 0.126) \mathrm{mg} / \mathrm{Kg}$. This value is below the critical value of $4.0 \mathrm{mg} / \mathrm{Kg}$ for total PAHs in 


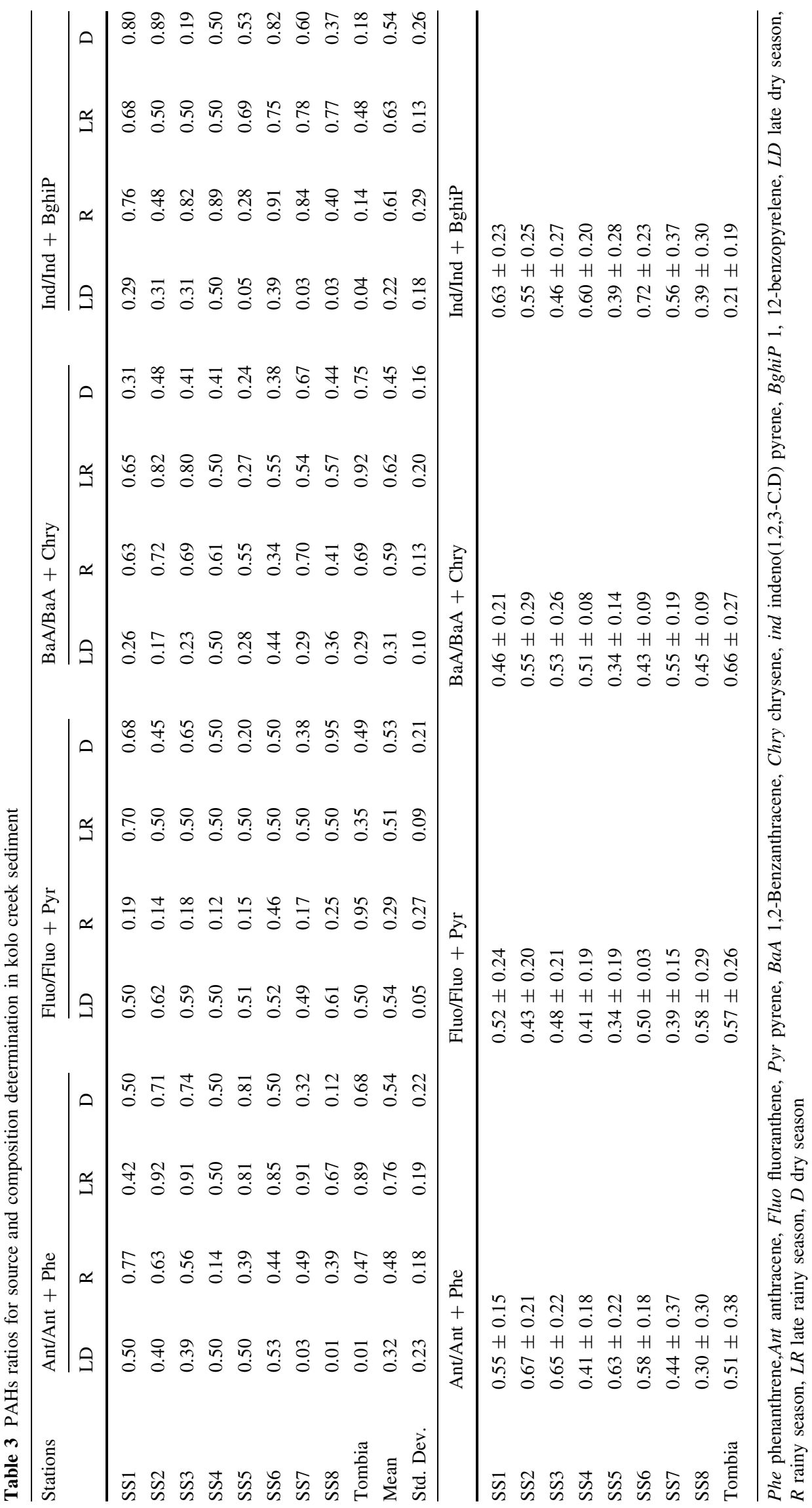


sediment (ANZECC 2000). According to MaliszewskaKordybach (1996), Kolo Creek sediment is classified as not contaminated. Comparing the levels of PAHs from this study with other studies in the Niger Delta reveal that Kolo Creek sediments had higher PAHs levels than Warri and Elelenwo (Olajire et al. 2005; Opuene et al. 2007) in the Niger Delta, but lower when compared with values from the other studies (Budzinski et al. 1997; Zhang et al. 2004).

The distribution of total PAHs in the study area is as follows: $\quad$ SS2 $>$ SS1 $>$ SS3 $>$ SS8 $=$ SS9 $>$ SS6 $=$ SS7 $>$ SS5 $>$ SS4, while the individual PAHs were in the order: Benzo(b) $\gg$ Chry $>$ BaP $>$ Benzo(k) $>$ Ind $>$ BghiP $>\mathrm{BaA}>$ Diben $>$ Naph $>$ Phe $=$ Fluo $>$ Ant $=$ Pyr $>$ Flu $>$ Acen $=$ Ace. The PAHs concentration ranged from $(0.00$ to $0.467) \mathrm{mg} / \mathrm{Kg}$. The highest PAHs concentration was observed in SS2 in the rainy season. PAHs concentration in the seasons follows the trend: late dry season $>$ rainy season $>$ dry season $>$ late rainy season.

Higher ringed PAHs (4-6) rings were more predominant than the lower ringed PAHs (2 and 3) rings, which is indicative of PAHs having pyrogenic origin.

The observed trend of PAHs concentrations in the various sampling stations is an indication that the flare within the proximity of SS1, SS2 and SS3 contributed greatly to PAHs in the environment as compared to other sources of PAHs in the other sampling stations.

PAHs sources were predicated using diagnostic ratios conventionally reported in literature (Yunker et al. 2002; Olajire and Brack 2005; Morillo et al. 2008). These ratios include Ant/Ant + Phe; Fluo/Fluo + Pyr; BaA/BaA + Chry And Ind/Ind + Bghip. The Ant/Ant + Phe ratio presumes that ratios $<0.1$ indicate PAHs source to be of petroleum origin, while ratios $>0.1$ indicate PAHs source to be of combustion origin (Budzinski et al. 1997). The Fluo/Fluo + Pyr ratio presumes that ratios in the range $\geq 0.4$ and $\leq 0.5$ indicate petroleum combustion and ratios $<0.4$ indicate petroleum sources, while ratios $>0.5$ indicate grass, wood and coal combustion. $\mathrm{BaA} / \mathrm{BaA}+$ Chry presumes that ratios $<0.2$ are of petroleum origin, ratios in the range $\geq 0.2$ and $\leq 0.35$ as mixed sources and $>0.35$ as combustion sources. Lastly, Ind/Ind + BghiP presumes that PAHs ratios $<0.2$ indicate petroleum sources, ratios in the range $\geq 0.2$ and $\leq 0.5$ as petroleum combustion sources and $>0.5$ as grass, wood and coal combustion sources (Budzinski et al. 1997; Yunker et al. 2002; Olajire et al. 2005; Morillo et al. 2008). These ratios and their cut-off values for the various predicted sources explicitly elaborated into (Fig. 2) five for the four periods of the year that the study was conducted. Applying a single PAH ratio may not be adequate and can be misleading (Yunker et al. 2002). This, however, is ameliorated by the use of PAH cross plots to enable the determination of PAH sources.
In the late dry season (cf. Fig. 2), the PAHs cross plots separated the sampling stations into groups of possible PAH sources. In (Fig. 2), BaA/BaA + Chry versus Fluo/ Fluo + Pyr, two major groups were observed, the largest having four sampling stations (SS1; SS3; SS5 and SS9) and a likely PAH source of mixed sources/grass, wood and coal combustion. While the second largest group has two sampling stations (SS6 and SS8) with a likely PAH source of combustion/grass, wood and coal combustion. The other groups had single sampling stations. Sampling Station 4(SS4) had possible PAH source of petroleum combustion/ combustion, SS7 had Mixed sources/petroleum combustion, while SS2 had petroleum/grass, wood and coal combustion.

Sampling Station 1 (SS1) in the late dry season exhibited combustion as sources of PAHs. The combustion is combined petroleum and wood combustion. This is expected for petroleum combustion, since SS1 is the point at which the gas flare is situated. It therefore corresponds with petroleum combustion. Also, grass, wood and coal combustion were predicted as sources of PAHs. This also corresponds with human activities in the vicinity because the host communities of the flow station (Imiringi) and the other bordering communities main source of energy for cooking and other domestic activities is firewood. Also, some minor bush clearing and burning may have contributed to the prediction that grass, wood and coal combustion is a source of PAHs in SS1. Morillo et al. (2008) determined PAHs sources based on the land use, they, however, observed no correlation between the land use and the sources of PAHs basically because of the ubiquitous nature of PAHs, but were able to conclude that PAHs of pyrogenic origin were the major sources of PAHs.

Imiringi (SS4) which is a habited community with all its attendant activities tends to stand out. Its sources of PAHs were combustion, petroleum combustion, grass, wood and coal combustion and petroleum. This could be ascribed to the multifaceted activities embarked upon by inhabitants of this community such as bush burning (Masclet et al. 1995) and generation of energy through the combustion of fossil fuels (Oros and Simoneit 2000). This is similar to SS7 (Otuasega) and SS8 (Oruma) that have settings like SS4 (Imiringi). SS2, SS3, SS5 and SS6 were also similar in their sources of PAHs and closely resemble that of SS1. These stations lie along the creek in parts that traverse farmlands.

In the rainy season (cf. Fig. 3), majority of the sampling stations fell between petroleum and combustion sources, which can be regarded as mixture of extreme sources. Within this area, Kolo Creek serves as the major drainage and all the rain water finally flow through their courses to Kolo Creek. It is likely that petroleum products such as fuel and lubricating oil both in use and as wastes were washed 
Fig. 2 PAH cross plots for the varios ratios in the late dry season

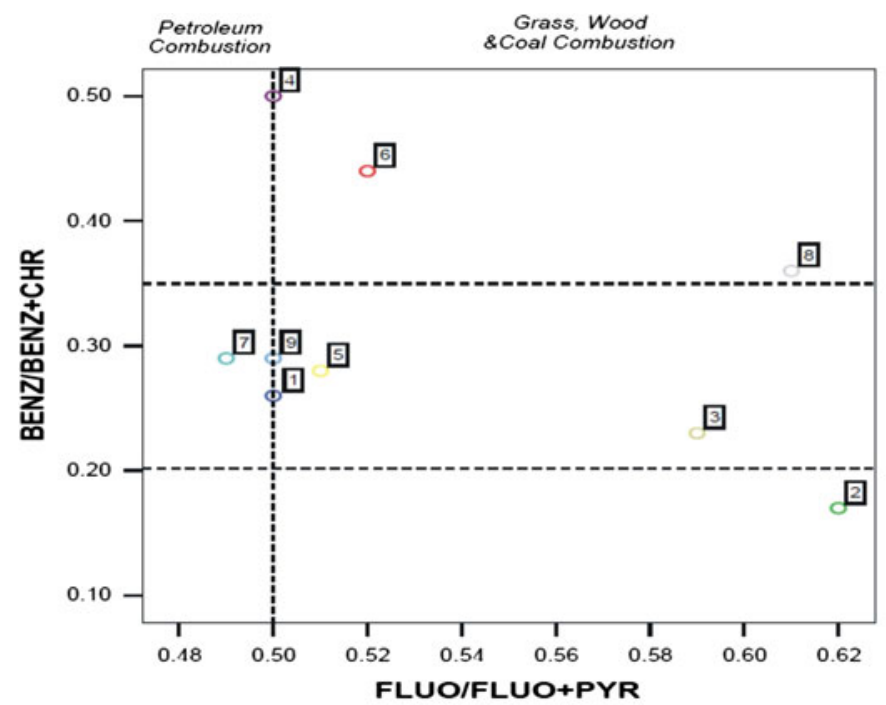

Combustion

Mixed Sources

samplingstations

ss1

SS2

Ss 3

Petroleum Ss

SS6

SS7

TOMBIA

FLUO/FLUO+PYR

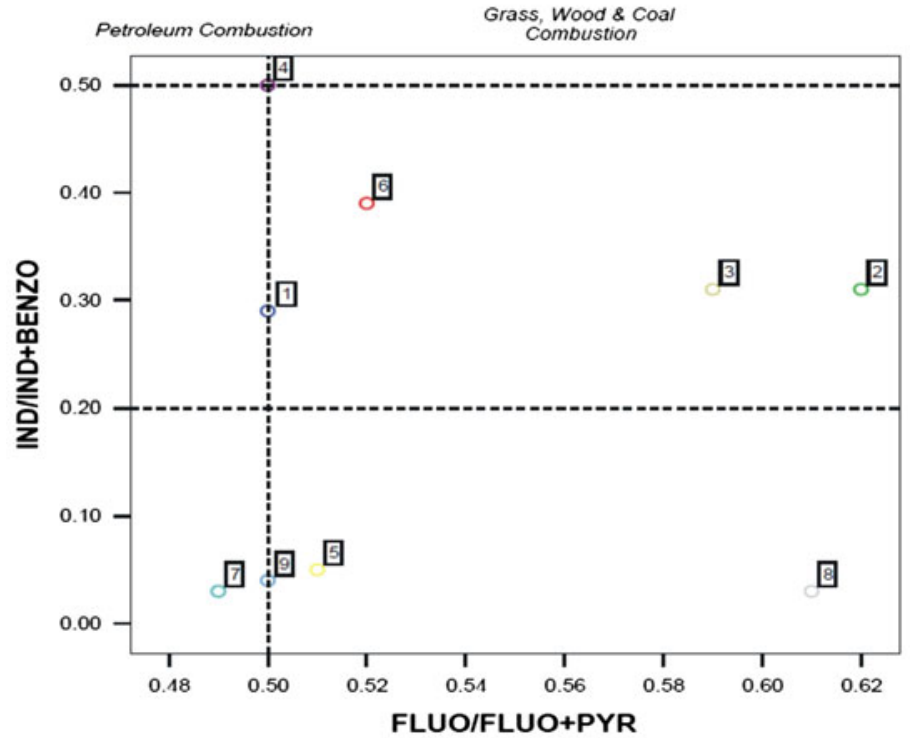

Grass, Wood \& Coa Combustion

Petroleum Combustion

Petrolec

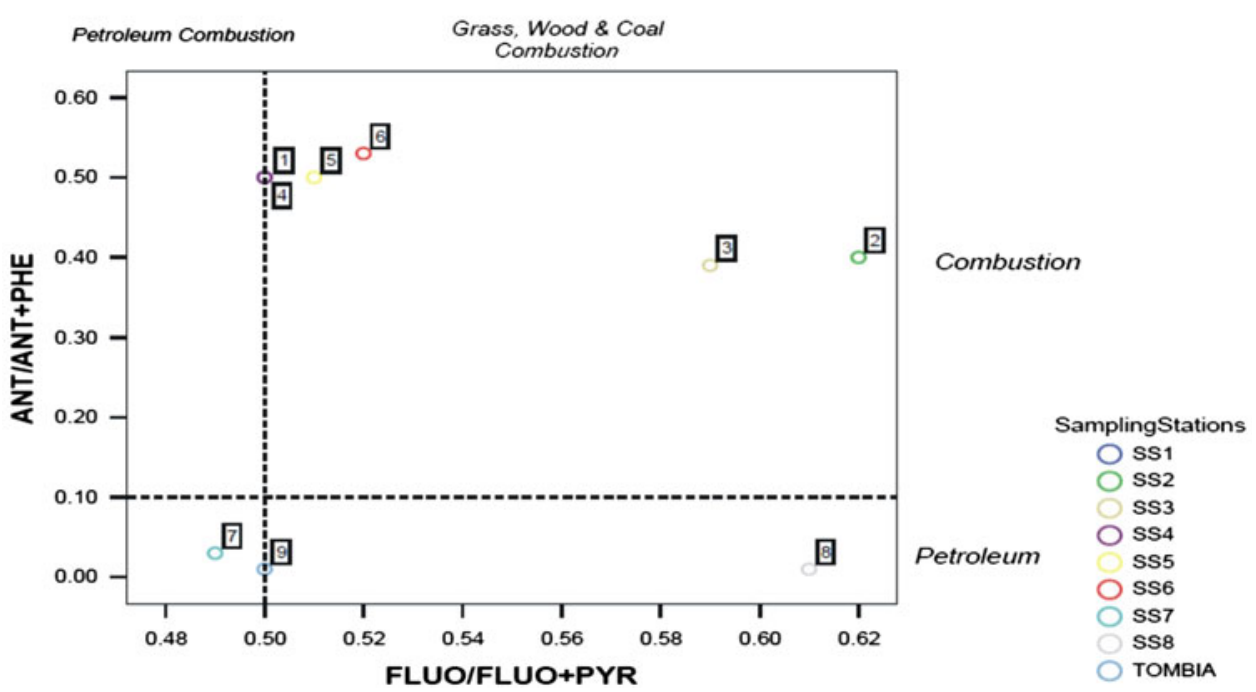

Combustion

plingstations

Ss 1

Petroleum

ss 3

Ss4

SS5

Ss6

ss7

SS8

TOMBIA 
Fig. 3 PAH cross plots for the various ratios in the rainy season

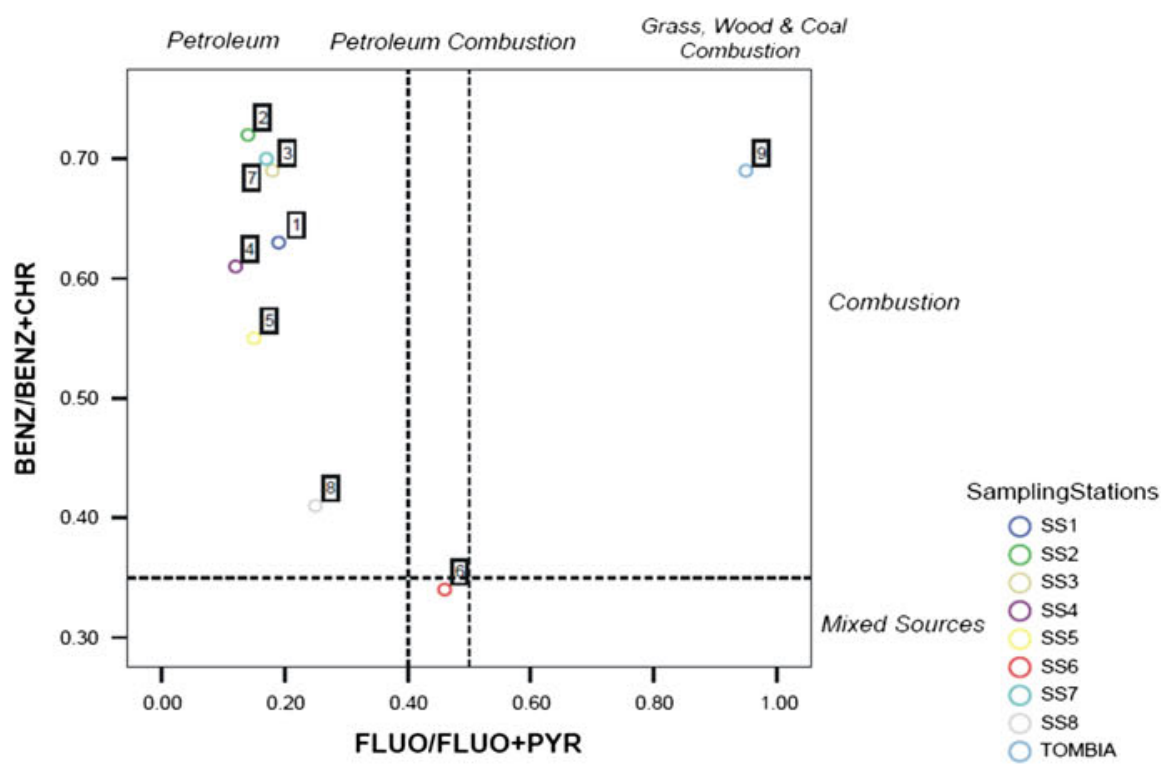

PAH CROSS PLOT FOR RATIOS IND/IND+BENZO VS FLUO/FLUO+PYR
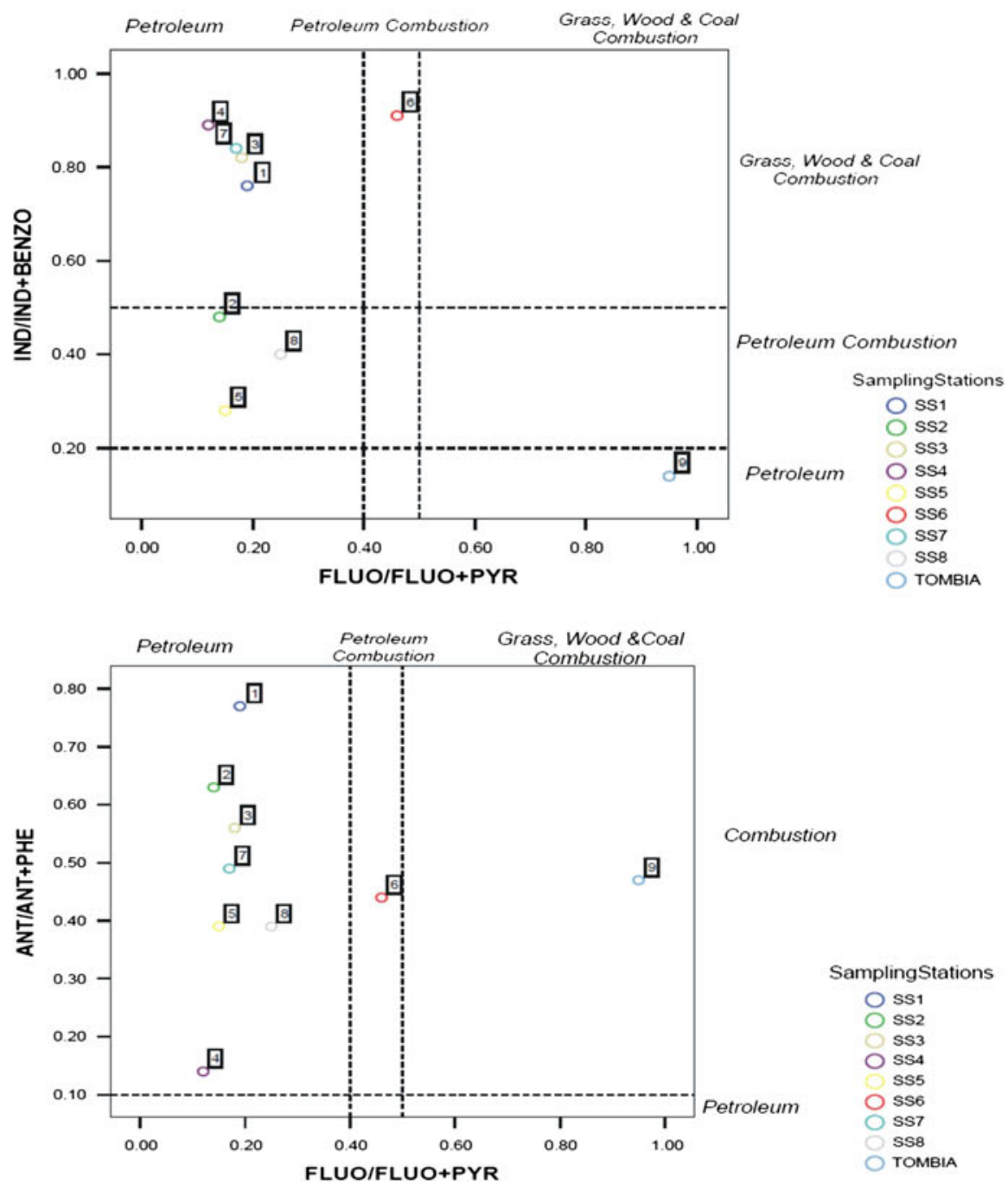
down into the creek (Laflamme and Hites 1978), thus contributing greatly to the sources of PAHs in Kolo Creek in the Rainy season to be more of petroleum origin. Karlsson and Viklander (2008) reported similarly that Gully Pots water and sediment which were mainly drained from the city centre had mixed sources of PAHs, because the drains collect all manner of waste from the environment. Wang et al. (2010) also reported similar findings.

Tombia Junction (SS9) which is situated close to an abattoir and a petrol station mainly indicated combustion (grass and wood combustion) and petroleum as sources of PAHs in SS9 situated in Epie Creek. This is expected due to high level of wood burning during the preparation of the meat in this abattoir and the fuel and other petroleum products that were likely washed-off and drained into the creek. This observation is consistent with the findings of Olajire and Brack (2005). In their study, soil samples collected from a fuel tanker loading point had PAHs ratios that were indicative of petrogenic origins.

SS6 had a vividly established source of petroleum/petroleum combustion in all the three cross PAHs ratios, which strongly indicated some form of power generation and automobile vehicular activities. During the period of sampling, a bridge construction was on-going at SS6 where heavy duty vehicles were in use. This may have contributed to petroleum/petroleum combustion source of PAHs at SS6.

In the late rainy season (cf. Fig. 4), the major group was combustion/petroleum combustion. Grass, wood and coal combustion also contributed. SS9 was classified to have PAHs sources as petroleum/petroleum combustion, while SS1 was combustion/grass, wood and coal combustion. The other stations were classified as more of petroleum combustion. The sampling stations except SS1 and SS9 had PAHs sources similar to those of the rainy season. Sampling Stations SS1 and SS9 having PAHs sources of wood combustion and petroleum combustion, respectively, is linked to the activities in the immediate environment. SS1 is the flare point and SS9 lies along a busy road with heavy vehicular traffic in the heart of Yenagoa Metropolis. It is, therefore, expected that some of the PAHs may have condensed, and dissolved in rain water, bound to particles and eventually flow to the creek to form sediments.

In the dry season, the PAHs cross plots separated the sampling stations as shown in Fig. 5.

Majority of the stations in the dry season fell under petroleum combustion and also in the broad class of combustion. SS5 fell under petroleum in all three ratio cross plots. This is a strong indication that there may have been some release of petroleum products into the environment during this period of sampling. However, in the dry season, airborne PAHs travel far and wide, and therefore, it is expected that mixed sources of PAHs will more likely represent PAHs in the dry season. Wania and Mackay (1996) reported similarly that gaseous and particle bound PAHs can be transported over long distances before deposition, especially at low relative humidity. This phenomenon can generate a pot-pouri of PAHs with diverse origins.

The annual modal PAHs sources in the various sampling stations are summarised in Table 4. Most of the sampling stations had combustion as the major source of PAHs in all the seasons of the year. This is a combination of petroleum combustion and grass, wood and coal combustion, which had equal contributions in the considered sampling stations. The in next ranking to combustion (petroleum and wood) is petroleum and the least in ranking is mixed sources.

Sampling station 9 (SS9) had petroleum as an outstanding source of PAHs. As earlier stated, this may have been as a result of the contribution from fuel station that is adjacent to the sampling station. Also, SS9 lies along a busy road with high volume of automobile traffic in an urban setting and that may have contributed greatly to petroleum combustion being the next ranking PAHs source in SS9.

From the literature values in Table 5, the likely predominant PAH sources in Kolo Creek are of petroleum origin (diesel and lubricating oil) in the rainy season. In the other seasons, there was no corresponding petroleum source when values from this study were compared with the literature values. It is suggested that during the rainy season, the storm water would have washed-off diesel and lubricating oil from various sources and drained to the creek. Comparing DR values of this study with literature values reveal that the likely combustion sources were wood/grass and gasoline combustion in all the seasons that the study was conducted except in the rainy season.

The petroleum source from literature that was close to the values obtained in this study is the fluo/fluo + pyr ratio for kerosene (0.46). SS2, SS3 and SS4 had 0.43, 0.48 and 0.41 , respectively. The literature value for kerosene for the ind/ind + BghiP ratio was 0.48 . The value for SS3 $(0.48)$ was closest to it. SS1 and SS2 had $0.63 \pm 0.23$ and $0.55 \pm 0.25$, respectively. In general, the values were also close to literature values for diesel, $(0.26 \pm 0.16)$ for fluo/ fluo + pyr and $0.40 \pm 0.18$ ) for ind/ind + BghiP.

The environmental samples sources from literature that were close to values from this study are bush fire $(0.61$ and $0.70)$; lubricating oil re-refined (0.74 and 0.36$)$; used engine oil (gasoline cars) ( 0.30 and 0.18 ) and used engine oil (diesel cars) (0.37 and 0.29) for fluo/fluo + pyr and ind/ ind + BghiP, respectively.

The literature values for combustion sources that were close to values from this study were those for: grasses; wood; kerosene; gasoline and diesel combustion (cf. 3 and 5). All the sampling stations had elements of combustion; however, for environmental samples SS1 pronounced bush fire as a source of PAHs, while SS4 and SS5 showed used oil as sources of PAHs. 
Fig. 4 PAH cross plots for the various ratios in the late rainy season
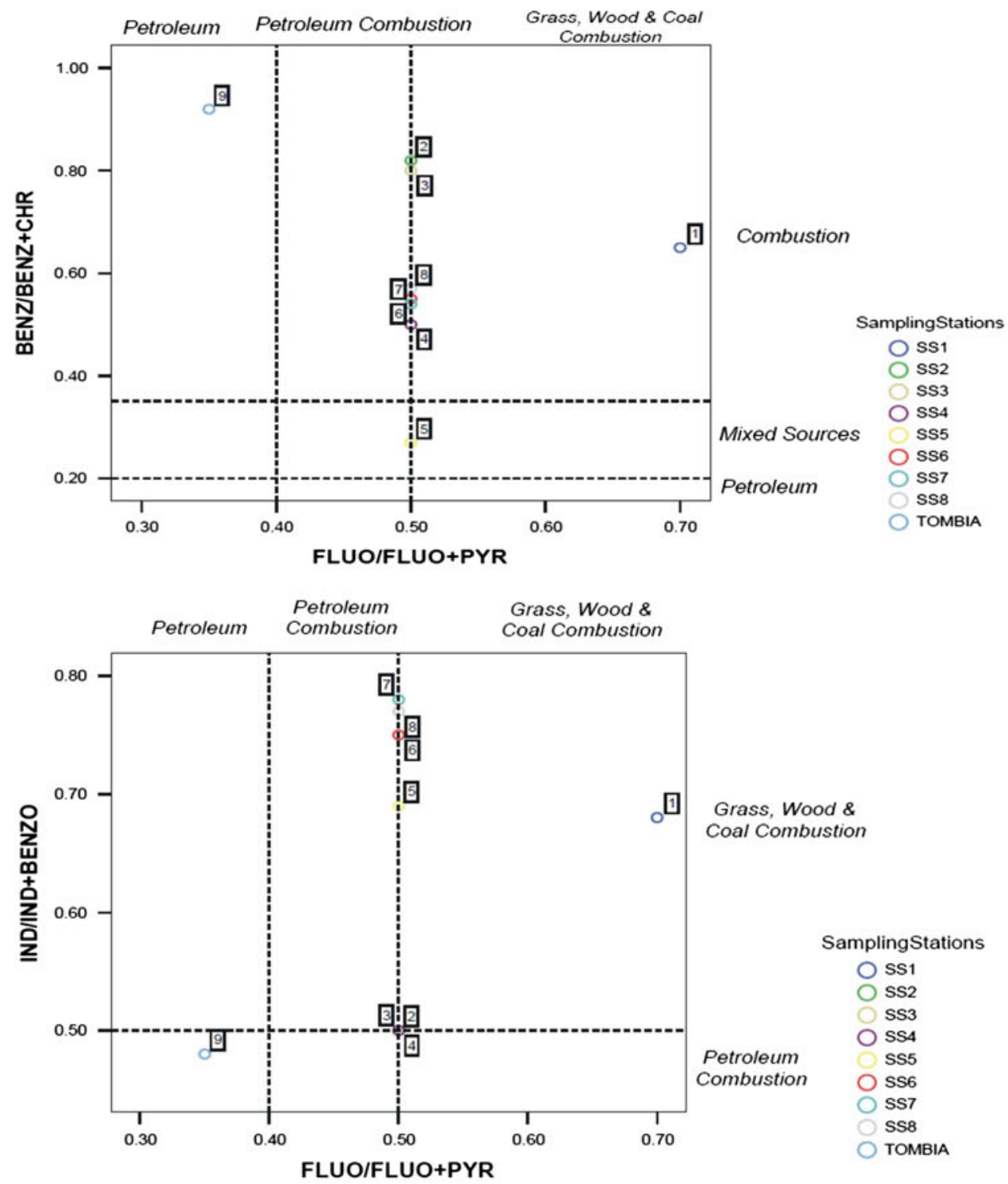

Grass, Wood \& Coal Combustion

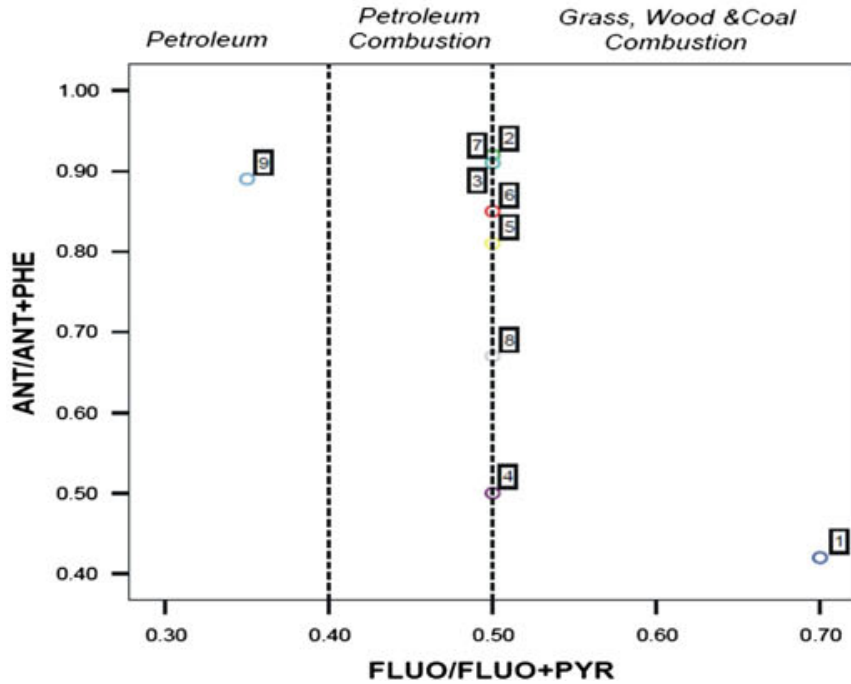

Combustion

SamplingStations

Ss1

is 2

ss 3

ss4

ss5

ss6

sst

ss8

TOMBIA 
Fig. 5 PAH cross plots for the various ratios in the dry season
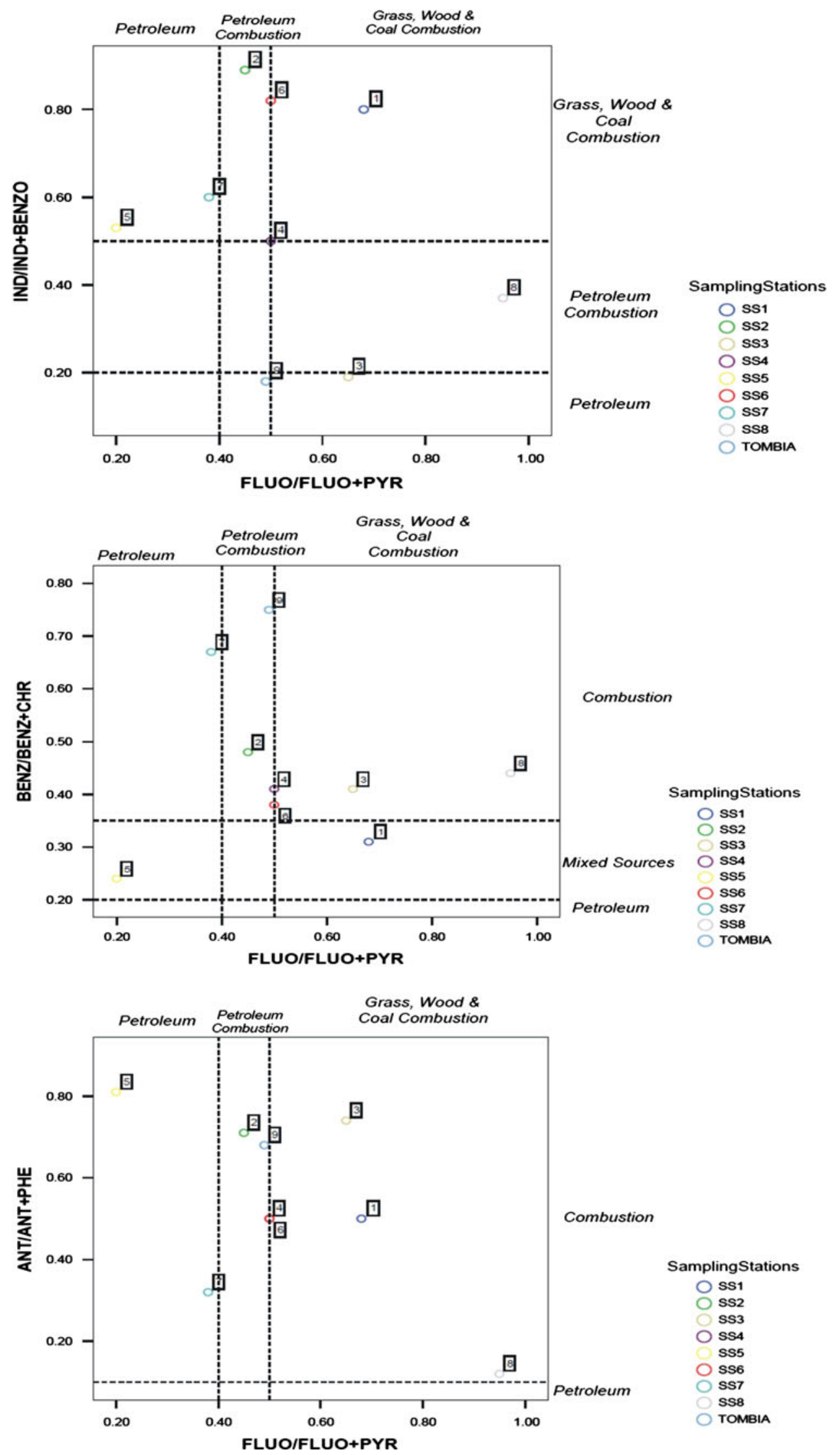
Table 4 Identified PAHs Sources in the Sampling Stations for the Various Seasons

\begin{tabular}{|c|c|c|c|c|c|}
\hline & Petroleum & Petroleum combustion & $\begin{array}{l}\text { Grass, wood \& coal } \\
\text { combustion }\end{array}$ & Combustion & Mixed sources \\
\hline $\begin{array}{r}\text { Late dry } \\
\text { season }\end{array}$ & SS2, SS7, SS9, SS5, SS8 & $\begin{array}{l}\text { SS1, SS3, SS4, SS6, SS7, } \\
\quad \text { SS9 }\end{array}$ & $\begin{array}{l}\text { SS1, SS2, SS3, SS5, } \\
\text { SS6, SS8, SS9 }\end{array}$ & $\begin{array}{l}\text { SS1, SS2, SS3, SS4, SS5, } \\
\text { SS6, SS8 }\end{array}$ & $\begin{array}{l}\text { SS1, SS3, SS5, } \\
\text { SS7, SS9 }\end{array}$ \\
\hline $\begin{array}{l}\text { Rainy } \\
\text { season }\end{array}$ & $\begin{array}{l}\text { SS1, SS2, SS3, SS4, SS5 } \\
\text { SS6, SS7, SS8, SS9 }\end{array}$ & SS2, SS5, SS6 & $\begin{array}{l}\text { SS1, SS3, SS4, SS7, } \\
\text { SS9 }\end{array}$ & $\begin{array}{l}\text { SS1, SS2, SS3, SS4, SS5 } \\
\text { SS6, SS7, SS8, SS9 }\end{array}$ & SS6 \\
\hline $\begin{array}{l}\text { Late rainy } \\
\text { season }\end{array}$ & SS9 & $\begin{array}{l}\text { SS2, SS3, SS4, SS5, SS6, } \\
\text { SS7, SS8, SS9 }\end{array}$ & $\begin{array}{l}\text { SS1, SS5, SS6, SS7, } \\
\text { SS8 }\end{array}$ & $\begin{array}{l}\text { SS1, SS2, SS3, SS4, SS5 } \\
\text { SS6, SS7, SS8, SS9 }\end{array}$ & SS5 \\
\hline Dry season & SS3, SS5, SS7, SS9 & SS2, SS4, SS6, SS8, SS9 & $\begin{array}{l}\text { SS1, SS3, SS5, SS7, } \\
\text { SS8 }\end{array}$ & $\begin{array}{l}\text { SS1, SS2, SS3, SS4, SS5 } \\
\text { SS6, SS7, SS8, SS9 }\end{array}$ & SS1, SS5 \\
\hline \multirow{9}{*}{$\begin{array}{l}\text { Annual } \\
\text { frequency }\end{array}$} & $\mathrm{SS} 1=1$ & $\mathrm{SS} 1=1$ & $\mathrm{SS} 1=4$ & $\mathrm{SS} 1=4$ & $\mathrm{SS} 1=2$ \\
\hline & $\mathrm{SS} 2=2$ & $\mathrm{SS} 2=3$ & $\mathrm{SS} 2=1$ & $\mathrm{SS} 2=4$ & $\mathrm{SS} 2=0$ \\
\hline & $\mathrm{SS} 3=2$ & $\mathrm{SS} 3=2$ & $\mathrm{SS} 3=3$ & $\mathrm{SS} 3=4$ & $\mathrm{SS} 3=1$ \\
\hline & $\mathrm{SS} 4=1$ & $\mathrm{SS} 4=3$ & $\mathrm{SS} 4=1$ & $\mathrm{SS} 4=4$ & $\mathrm{SS} 4=0$ \\
\hline & $\mathrm{SS} 5=3$ & $\mathrm{SS} 5=2$ & $\mathrm{SS} 5=3$ & $\mathrm{SS} 5=4$ & $\mathrm{SS} 5=3$ \\
\hline & $\mathrm{SS} 6=1$ & $\mathrm{SS} 6=4$ & $\mathrm{SS} 6=2$ & $\mathrm{SS} 6=4$ & $\mathrm{SS} 6=1$ \\
\hline & $\mathrm{SS} 7=3$ & $\mathrm{SS} 7=2$ & $\mathrm{SS} 7=3$ & $\mathrm{SS} 7=3$ & $\mathrm{SS} 7=1$ \\
\hline & $\mathrm{SS} 8=2$ & $\mathrm{SS} 8=2$ & $\mathrm{SS} 8=3$ & $\mathrm{SS} 8=4$ & $\mathrm{SS} 8=0$ \\
\hline & $\mathrm{SS} 9=4$ & $\mathrm{SS} 9=4$ & $\mathrm{SS} 9=2$ & $\mathrm{SS} 9=3$ & $\operatorname{SS} 9=1$ \\
\hline Total & 19 & 22 & 22 & 34 & 9 \\
\hline
\end{tabular}

Table 5 PAH ratios for petroleum, single source combustion and environmental samples
Adapted from Yunker et al. (2002)

\begin{tabular}{lll}
\hline Source & Fluo/Fluo + Pyr & Ind/Ind + BghiP \\
\hline Petroleum & & \\
Kerosene & 0.46 & 0.48 \\
Diesel oil & $0.26 \pm 0.16(0.01-0.47)$ & $0.40 \pm 0.18(0.25-0.65)$ \\
Crude oil & $0.22 \pm 0.07(0.14-0.26)$ & 0.09 \\
Lubricating oil & $0.29(0.17-0.30)$ & $0.12(0.00-0.13)$ \\
Asphalt & & $0.52-0.54$ \\
Combustion & & \\
Bituminous coal & $0.53 \pm 0.05(0.48-0.58)$ & $0.48(0.35-0.62)$ \\
Coal tar & 0.58 & 0.53 \\
Wood soot & 0.50 & 0.55 \\
Wood & $0.51 \pm 0.06(0.41-0.67)$ & $0.64 \pm 0.07(0.49-0.77)$ \\
Grasses & $0.58 \pm 0.04(0.53-0.63)$ & $0.58 \pm 0.10(0.52-0.69)$ \\
Gasoline & 0.44 & $0.09-0.22$ \\
Kerosene & 0.50 & 0.37 \\
Diesel & $0.39 \pm 0.11(0.20-0.58)$ & $0.35 \pm 0.1(0.19-0.50)$ \\
Crude oil & $0.44 \pm 0.02(0.42-0.46)$ & $0.47 \pm 0.01(0.46-0.48)$ \\
Environmental samples & & \\
Bush fire & 0.61 & 0.70 \\
Savannah fire particulate & $0.59 \pm 0.01(0.58-0.60)$ & $0.39 \pm 0.07(0.31-0.44)$ \\
Road dust & 0.42 & 0.51 \\
Lubricating oil, re-refined & 0.74 & 0.36 \\
Used engine oil (gasoline car) & 0.30 & 0.18 \\
Used engine oil (diesel car) & 0.37 & 0.29 \\
Urban air & $0.56 \pm 0.01(0.55-0.57)$ & $0.40 \pm 0.11(0.27-0.48)$ \\
Creosote treated wood pilling & $0.62 \pm 0.01(0.61-0.64)$ & $0.64 \pm 0.04(0.59-0.68)$ \\
\hline
\end{tabular}




\section{Conclusion}

The major anthropogenic sources of PAHs in the sediment of Kolo Creek were of pyrogenic origin. There were, however, petrogenic sources that were close to point sources as in the case of SS9 that is in the proximity of a petrol station and also in the rainy season that petroleum products were allegedly washed into the creek by storm water. The pyrogenic sources were a combination of grass/ wood combustion and petroleum combustion. These predictions corresponded with the types of activities within the vicinity of the sampling stations in question. This study further affirms the accuracy of the predictive use of diagnostic ratios of PAHs for source determination.

Acknowledgments The authors are grateful to Shell Petroleum Development Company of Nigeria Limited and Technology Partners International for their technical support in the aspects of sampling and laboratory analysis.

\section{References}

Aichner B, Glaser B, Zech W (2007) Polycyclic aromatic hydrocarbons and polychlorinated biphenyls in urban soils from Kathmandu. Nepal Org Geochem 38(4):700-715

Ana GREE, Sridhar MKC, Emerole GO (2009) A comparative assessment of soil pollution by polycyclic aromatic hydrocarbons in two Niger Delta communities, Nigeria. Afr J Pure Appl Chem $3(3): 31-41$

ANZECC (2000) Australian and New Zealand guidelines for fresh and marine water quality. Australian and New Zealand Environment and Conservation Council

Budzinski H, Jones I, Bellocq J, Pie'rard C, Garrigues P (1997) Evaluation of sediment contamination by polycyclic aromatic hydrocarbons in the Gironde estuary. Mar Chem 58(1-2):85-97

Dvorska A, Lammel G, Klanova J (2011) Use of diagnostic ratios for studying source apportionment and reactivity of ambient polycyclic aromatic hydrocarbons over Central Europe. Atmos Environ 45(2):420-427

Fine PM, Cass GR, Simoneit BR (2001) Chemical characterization of fine particle emissions from fireplace combustion of woods grown in the northeastern United States. Environ Sci Technol 35(13):2665-2675

Halsall CJ, Sweetman AJ, Barrie LA, Jones KC (2001) Modelling the behaviour of PAHs during atmospheric transport from the UK to the Arctic. Atmos Environ 35(2):255-267

Inengite AK, Oforka NC, Osuji Leo C (2010a) Survey of heavy metals in sediments of Kolo creek in the Niger Delta, Nigeria. Afr J Environ Sci Tech 4(9):558-566

Inengite AK, Oforka NC, Osuji Leo C (2010b) Evaluation of polycyclic aromatic hydrocarbons in sediment of Kolo Creek in the Niger Delta. Int J Appl Environ Sci 5(1):127-143

Karlsson K, Viklander M (2008) Polycyclic aromatic hydrocarbons(PAH) in water and sediment from Gully Pots. Water Air Soil Poll 188(1-4):271-282

Laflamme RE, Hites RA (1978) The global distribution of polycyclic aromatic hydrocarbons in recent sediments. Geochim Cosmochim Ac 42(3):289-303

Lehndorff E, Schwark L (2004) Biomonitoring of air quality in the cologne conurbation using pine needles as a passive sampler- part II: polycyclic aromatic hydrocarbons (PAH). Atmos Environ 38(23):3793-3808

Li CK, Kamens RM (1993) The use of polycyclic aromatic hydrocarbons as source signatures in receptor modeling. Atmos Environ 27(4):523-532

Lunde G, Bjorseth A (1977) Polycyclic aromatic hydrocarbons in long-range transported aerosol. Nature 268:518-519

Maliszewska-Kordybach B (1996) Polycyclic aromatic hydrocarbons in agricultural soils in Poland: preliminary proposals for criteria to evaluate the level of soil contamination. Appl Geochem 11(1-2):121-127

Masclet P, Cachier H, Liousse C, Wortham H (1995) Emissions of polycyclic aromatic hydrocarbons by savanna fires. J Atmos Chem 22(1-2):41-54

Morillo E, Romero AS, Madrid L, Villaverde J, Maqueda C (2008) Characterization and sources of PAHs and potentially toxic metals in urban environments of Sevilla (Southern Spain). Water Air Soil Poll 187(1-4):41-51

Olajire AA, Brack W (2005) Polycyclic aromatic hydrocarbons in Niger Delta Soil: contamination sources and profiles. Int J Environ Sci Tech. 2(7):343-352

Olajire AA, Altenburger R, Kuster E, Brack W (2005) Chemical and ecotoxological assessment of polycyclic aromatic hydrocarboncontaminated sediments of the Niger Delta, Southern Nigeria. Sci Total Environ 340(1-3):123-136

Opuene K, Agbozu IE, Ekeh LE (2007) Identification of perylene in sediments: occurrence and diagenetic evolution. Int $\mathrm{J}$ Environ Sci Tech 4(4):457-462

Oros DR, Simoneit BR (2000) Identification and emission rates of molecular tracers in coal smoke particulate matter. Fuel 79(5): $515-536$

Re'-Poppi N, Santiago-Silva M (2005) Polycyclic aromatic hydrocarbons and other selected organic compounds in ambient air of Campo Grande City, Brazil. Atmos Environ 39(16):2839-2850

Readman JW, Mantoura RF, Rhead MM (1987) A record of polycyclic aromatic hydrocarbon $(\mathrm{PAH})$ pollution obtained from accreting sediments of the Tamar estuary, UK: evidence for nonequilibrium behaviour of PAH. Sci Total Environ 66:73-94

Sjogren M, Li H, Rannug U, Westerholm R (1996) Multivariate analysis of exhaust emissions from heavy-duty diesel fuels. Environ Sci Technol 30(1):38-49

Tamuno PBL (2005) Eco-livelihood assessment of inland river dredging: the Kolo and Otuoke creeks, Nigeria, a case study. Ph.D Dissertation, Loughborough University, UK

Wang Z, Fingas M, Shu YY, Sigouin L, Landriault M, Lambert P, Turpin R, Campagna P, Mullin J (1999) Quantitative characterization of PAHs in burn residue and soot samples and differentiation of pyrogenic PAHs from petrogenic PAHs-the 1994 Mobile burn study. Environ Sci Technol 33(18):3100-3109

Wang XU, Li QB, Luo YM, Ding Q, Xi LM, Ma JM, Liu YP, Cheng CL (2010) Characteristics and sources of atmospheric polycyclic aromatic hydrocarbons (PAHs) in Shanghai, China. Environ Monit Assess 165:295-305

Wania F, Mackay D (1996) Tracking the distribution of persistent organic pollutants. Environ Sci Technol 30(9):390A-396A

Westerholm RN, Li H (1994) A multivariate statistical analysis of fuel-related polycyclic aromatic hydrocarbon emissions from heavy-duty diesel vehicles. Environ Sci Technol 28(5):965-972

Yunker MB, Macdonald RW, Vingarzan R, Mitchell H, Goyette D, Sylvestre S (2002) PAHs in the Fraser River basin: a critical appraisal of PAHs ratios as indicators of PAH source and composition. Org Geochem 33(4):489-515

Zhang Z, Huang J, Yu G, Hong H (2004) Occurrence of PAHs, PCBs and organochlorine pesticides in the Tonghui River of Beijing, China. Environ Pollut 130(2):249-261 